\section{ELABORAÇÃO E VALIDAÇÃO DO JOGO DO PALITO NO ENSINO DE NOMENCLATURA DE COMPOSTOS ORGÂNICOS}

\section{Development and validation of Sticks Game to teaching nomenclature of organic compounds}

Elaboración y validación del Juego de palitos en la enseñanza de la nomenclatura de compuestos orgánicos

Resumo

O uso de jogos didáticos pode propiciar ao aluno o protagonismo no processo de ensino-aprendizagem. Contudo, faz-se necessária a validação do jogo quanto aos propósitos educacionais e lúdicos, além da viabilidade de seu uso no ensino básico. Este trabalho apresenta os resultados da validação do Jogo dos Palitos (elaborado pelos autores) e sua acessibilidade à sala de aula. Para isso, aplicamos o jogo em uma turma do 6o período do curso de Química Licenciatura da UFPE e analisamos, durante o jogo, o desempenho dos participantes em propor e nomear compostos orgânicos representados por fórmulas linhas de ligação, bem como os comportamentos e interações dos alunos. Observamos que o Jogo dos Palitos pode ser classificado de baixo custo e que não demanda tempo de preparo. Do ponto de vista da validação, constatou-se uma crescente melhora no desempenho dos alunos em nomear os compostos, que atribuímos à autorregulação do nível do desafio impelido pelos próprios alunos, à qualidade da interação promovida no jogo e ao ambiente livre de pressão característico da atividade.

Palavras-Chave: Jogo didático; Fórmula de linhas de ligação; Nomenclatura de compostos orgânicos.

\begin{abstract}
The use of didactic games can provide the student the protagonism in the teaching-learning process. However, it is necessary to validate the game for educational and recreational purposes, as well as the viability of its use in basic education. This paper presents the results of the validation of the of Sticks Game (elaborated by the authors) and its accessibility to the classroom. For this, we applied the game to a class from the 6th period of Chemistry Degree of UFPE and during the game we analyzed the performance of the participants in proposing and naming organic compounds represented by skeletal formulas, as well as the behaviors and interactions of the students. We note that the Sticks Game can be classified as low cost and does not require preparation time. From the point of view of validation, there was a growing improvement in students' performance in naming the compounds, which we attributed to the self-regulation of the level of challenge propelled by the students themselves, to the quality of the interaction promoted in the game and to the pressure-free environment characteristic of activity. Keywords: Didactic game; Skeletal formula; Nomenclature of organic compounds.
\end{abstract}

\section{Resumen}

El uso de juegos didácticos puede dar protagonismo al alumno en el proceso de enseñanza-aprendizaje. Sin embargo, el juego debe validarse en cuanto a los propósitos educativos y lúdicos y en la viabilidad de su utilización en la educación básica. Este trabajo presenta los resultados de la validación del Juego de los Palitos (elaborado por los autores) y de su accesibilidad al aula. Para ello, el juego se presentó a un grupo del sexto periodo de la Licenciatura en Química de la UFPE y se analizó, durante el transcurso del juego, el desempeño de los participantes en la proposición y nombramiento de compuestos orgánicos, así como también los comportamientos e interacciones de los alumnos. Observamos que el Juego puede clasificarse como de bajo costo y que no requiere tiempo de preparación. Con respecto a la validación, se constató una mejora creciente en el desempeño de los alumnos lo cual atribuimos a la autorregulación del nivel de desafío impulsado por los propios alumnos, la calidad de la interacción y al ambiente libre de presión característico de la actividad.

Palabras clave: Juego didáctico; Fórmula de línea-enlace; Nomenclatura de compuestos orgánicos.

\section{AUTORES:}

\section{JOSÉ AYRON LIRA DOS}

ANJOS

ORCID 0000-0002-0419-9323

${ }^{1}$ Universidade Federal de Pernambuco

(UFPE)

\section{RICARDO LIMA GUIMARÃES ${ }^{2}$}

ORCID 0000-0002-2019-4418

${ }^{2}$ Universidade Federal de Pernambuco

(UFPE)

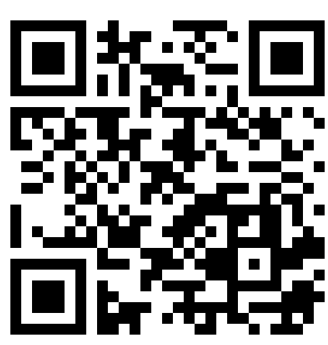

Para citar este artigo:
ANJOS, J. A. L.; GUIMARÃES, R. L. Elaboração e validação do jogo do palito no ensino de nomenclatura de compostos orgânicos. Revista Eletrônica Ludus Scientiae, Foz do Iguaçu, v. 01, n. 01, p. 163-174, jan./jul. 2017. 


\section{INTRODUÇÃO}

O ensino de química no ensino básico, sobretudo o de química orgânica, é ainda hoje pautado na memorização de fórmulas, leis e procedimentos de modo mecânico sem requerer a compreensão do aluno. Como consequência desta abordagem, o ensino dessa disciplina falha em promover o que deveria ser seu principal objetivo, que é introduzir o aprendiz nessa nova cultura a partir da apropriação da sua linguagem, fazeres e raciocínio. Adicionalmente esse processo em que o estudante é apartado da busca da compreensão, de dar sentido ao que se aprende, tem desmotivado cada vez mais os alunos e colocado em alerta todo o sistema escolar (MIRANDA; COSTA, 2007).

Acontece que estes objetos de conhecimento são passíveis de entendimento, visto que tanto foram elaborados para descrever e explicar propriedades (químicas e físicas) e transformações a partir da distribuição da densidade eletrônica na molécula resultando na precisa relação estrutura/propriedade, quanto foram construídos na necessidade de representar simbolicamente essas estruturas em uma inequívoca relação estrutura/nomenclatura.

Especificamente em se tratando da química orgânica, Roque e Silva (2008) destacam a impossibilidade do aprendizado dessa disciplina sem a devida compreensão do significado das várias representações estruturais simbólicas. Os mesmos autores alertam para as dificuldades não superadas pelos alunos ingressos na universidade decorrentes da abordagem meramente memorística com que tais representações são apresentadas no ensino médio, situação essa agravada no ensino superior, pois mesmo em cursos de formação de professores de química esse conteúdo é geralmente considerado como sabido ou simplesmente ignorado.

Rodrigues (2001) corrobora esse cuidado quando relata as muitas dúvidas formuladas por professores do ensino médio acerca das nomenclaturas dos compostos orgânicos e suas respectivas representações e ainda que, muitos alunos ingressantes trazem dificuldades consequência da desinformação e mesmo de vícios de "linguagem" no que se refere à sistemática da nomeação.

Um dos grandes desafios na aprendizagem da representação das cadeias carbônicas refere-se à utilização de fórmulas de linhas de ligação e à nomenclatura das estruturas orgânicas. Estas ações pertencem ao campo dos saberes procedimentais, pois se relacionam ao saber fazer e não simplesmente ao conhecer (WATANABE; RECENA, 2008; ZANON et. al, 2008).

Na representação por linhas de ligação, os estudantes normalmente apresentam dificuldades na determinação da quantidade de carbonos presentes na cadeia (principalmente em considerar os carbonos terminais) em decorrência de que neste modelo os elementos (carbonos e hidrogênios) são representados de forma implícita e apenas as ligações são explicitadas (figura 1).

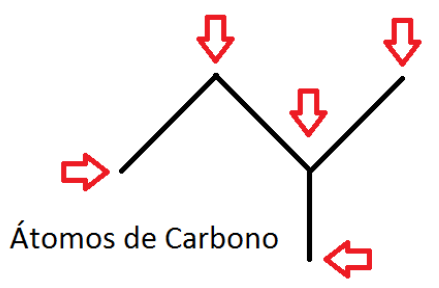

Figura 1: Representação de uma molécula orgânica por linhas de ligação (Fonte: Própria).

Quanto ao processo de nomear, observa-se que os estudantes apresentam facilidade quando se trata de cadeias carbônicas menores, mais simples e menos ramificadas. Contudo, à medida que se apresentam estruturas maiores e mais complexas, surgem dificuldades em designar a nomenclatura correta. Este problema é consequência de que com o aumento da complexidade da cadeia carbônica, mais regras são necessárias, sendo definidas pela União Internacional de Química Pura e Aplicada - 
IUPAC (International Union of Pure and Applied Chemistry) e, portanto, incorporadas à ação de nomear a cadeia para garantir a inequívoca relação nomenclatura-representação.

Para isso, todas as regras pertinentes devem ser observadas, tais como: a determinação da cadeia principal, a nomeação dos substituintes, a numeração da cadeia, a ordem com que esses substituintes devem ser dispostos no nome da estrutura orgânica. Este conjunto de normas muitas vezes não é observado pelos alunos como algo a ser compreendido e, portanto, eles não elaboram uma estratégia para a realização deste procedimento. Por conseguinte, a ação torna-se mecanizada e assim enfadonha e pouco atrativa aos estudantes.

Há também a deficiência referente à visualização espacial da estrutura química, o que leva os alunos a relacionar a cadeia principal a um conjunto de carbonos não necessariamente dispostos em uma direção horizontal. Esta visualização também requer uma estratégia de seleção fundamentada nas regras determinadas pela IUPAC (figura 2).
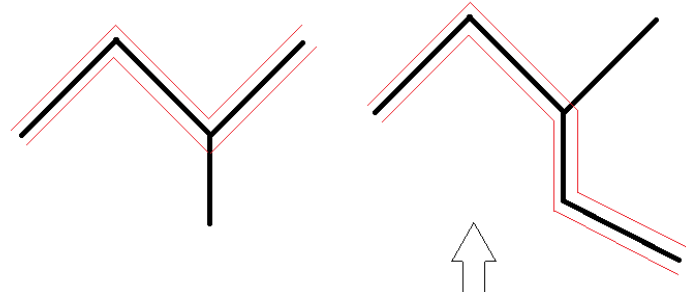

maior tendência a determinação

equivocada da cadeia principal

Figura 2: Disposição da cadeia principal em uma molécula orgânica (Fonte: Própria).

Mesmo nas universidades tem-se observado nos estudantes dificuldades e limitações no compreender e executar procedimentos mobilizando conhecimentos de química orgânica, o que segundo Rodrigues (2001) é resultado da resistência dos alunos à mudança na forma de pensar a disciplina.

Nesse contexto, torna-se cada vez mais importante o desenvolvimento/implementação/ avaliação de novos instrumentos e abordagens metodológicas centrados na participação ativa do estudante no processo de ensino-aprendizagem. Entendendo a participação ativa como a ação na qual é requerida não só execução das atividades por parte do aluno, mas complementarmente a busca de compreensão dos procedimentos, dos conceitos envolvidos e do significado das elaborações e resultados alcançados.

Essas abordagens, ditas metodologias ativas, são pautadas no entendimento de que a aprendizagem não ocorre como resultado direto e imediato de uma intervenção pedagógica, sendo na verdade um processo progressivo que envolve a construção e reconstrução de significados pelo próprio aluno, pois como afirma Mitre et. al (2008):

$\mathrm{O}$ ato de aprender deve ser, portanto, um processo reconstrutivo que permita o estabelecimento de diferentes tipos de relações entre fatos e objetos, desencadeando ressignificações/ reconstruções e contribuindo para sua utilização em diferentes situações (MITRE et. al, 2008, 2133).

O uso de jogos didáticos vem sendo amplamente implementado como estratégias de ensino voltadas ao ensino de conteúdos de química, muitas vezes na perspectiva de uma metodologia ativa de aprendizagem e tem apresentado uma grande aceitação por parte de professores e estudantes que apontam a motivação e a participação dos alunos como principal justificativa à atribuição de êxito da abordagem (SOARES, 2013; CUNHA ,2012; DOMINGOS; RECENA, 2010). 
Contudo, considerando o necessário equilíbrio entre as funções lúdica e educativa apontadas por Kishimoto (1998), faz-se necessária a validação do jogo no que se refere ao atendimento dos objetivos educacionais, seja relacionada à aprendizagem de conceitos ou procedimentos relacionados ao conteúdo, seja ao desenvolvimento das habilidades imprescindíveis à mobilização desse conhecimento.

Além disso, poucas pesquisas vêm sendo realizadas discutindo aspectos teóricos e produzindo um referencial teórico-metodológico acerca das características e contribuições do uso de jogos didáticos no ensino, com exceção de alguns poucos trabalhos, dentre os quais destacamos os de Garcez e Soares (2017), Soares (2013), Soares e Cavalcanti (2009), Cunha (2012) e Gouvêia e Suart (2014), orientando a elaboração de jogos e atividades lúdicas voltadas ao ensino de química no sentido de potencializar a construção de saberes e o desenvolvimento cognitivo.

Sendo assim, ao considerarmos os conhecimentos acumulados acerca das características do jogo e quais os mecanismos favorecem a aprendizagem nesta metodologia, podemos, no planejamento da atividade: otimizar a negociação de significados por meio da interação discursiva entre os alunos, fator essencial na compreensão de conceitos; propiciar a recursividade na exercitação de procedimentos, garantida a partir da ocorrência de um número suficiente de rodadas; ou ainda propiciar a ampliação da estabilidade cognitiva de algum conhecimento alcançada a partir da utilização de uma diversidade de contextos.

Outro aspecto fundamental no desenvolvimento metodológico de atividades de ensino é fornecer as condições para que essas metodologias e instrumentos elaborados, normalmente nas instituições de ensino superior, possam alcançar a sala de aula do ensino básico e ser útil à superação dos obstáculos presentes na realidade escolar.

Um dos aspectos que limitam a utilização de recursos alternativos designados ao ensino é o tempo e custo para a sua fabricação, uma vez que no caso dos jogos didáticos alguns desses materiais são produzidos a partir de brinquedos comerciais (por adaptação) e outros requerem a manufatura de peças e tabuleiros.

Nesse sentido, os autores desse trabalho elaboraram o jogo dos palitos, que utiliza apenas palitos de dente (ou qualquer outro tipo) para a aprendizagem dos procedimentos referentes à construção de cadeias carbônicas a partir da representação de linhas de ligação e à atribuição da nomenclatura adequada.

O presente trabalho tem por objetivo a validação do jogo dos palitos, tanto no êxito em alcançar os objetivos lúdicos e educacionais quanto na facilidade da sua implementação em sala de aula. Discutindo também a relação entre as situações de aprendizagem propiciadas a partir da dinâmica e regras do jogo e a compreensão dos princípios que regem a representação além do desenvolvimento de habilidades cognitivas e interpessoais. A escolha do conteúdo de fórmula de linhas de ligação e nomenclatura dos compostos orgânicos a ser tratado no jogo é justificada pelas dificuldades em alunos tanto do ensino médio quanto do ensino superior em compreender a significação das representações estruturais e a sistemática da nomeação de cadeias carbônicas destacada por relatadas por Rodrigues (2001) e Roque e Silva (2008).

\section{METODOLOGIA:}

“O jogo dos palitos" possibilita ao estudante o desenvolvimento de uma estratégia de construir e nomear cadeias carbônicas usando a representação de fórmula de linhas de ligação.

O JOGO: O jogo utiliza material de baixo custo, palitos de dente, que são utilizados para representar as ligações químicas na representação por linhas de ligação das cadeias carbônicas. 
AS REGRAS: Deve ser jogado individualmente por 4 a 6 competidores preferencialmente, dispostos em um círculo. O jogo se inicia quando um dos participantes (jogador 1) adiciona um palito (ligação) ao centro da mesa, e o próximo competidor (jogador 2) terá que nomear esta estrutura. Caso nomeie corretamente, o jogador 2 acrescentará mais um palito (ligação) à estrutura desafiando o participante seguinte (jogador 3) a nomeá-la e assim por diante. Caso, em algum momento, o jogador não saiba nomear a estrutura proposta como desafio pelo jogador que o antecedeu a tarefa (de nomear a estrutura) passa ao jogador desafiante (o que propôs a estrutura) levando a duas situações possíveis: (1) Caso o jogador desafiante nomeie a estrutura corretamente, o jogador desafiado estará eliminado e o jogo segue com o jogador desafiante acrescentando mais uma ligação à estrutura; ou (2) Caso o jogador desafiante não saiba nomear a estrutura que propôs, ele próprio será eliminado e o jogo segue com o jogador desafiado modificando a posição de uma ligação e desafiando o jogador seguinte a indicar a nomenclatura correta (figura 3). O jogo segue até só restar um competidor.

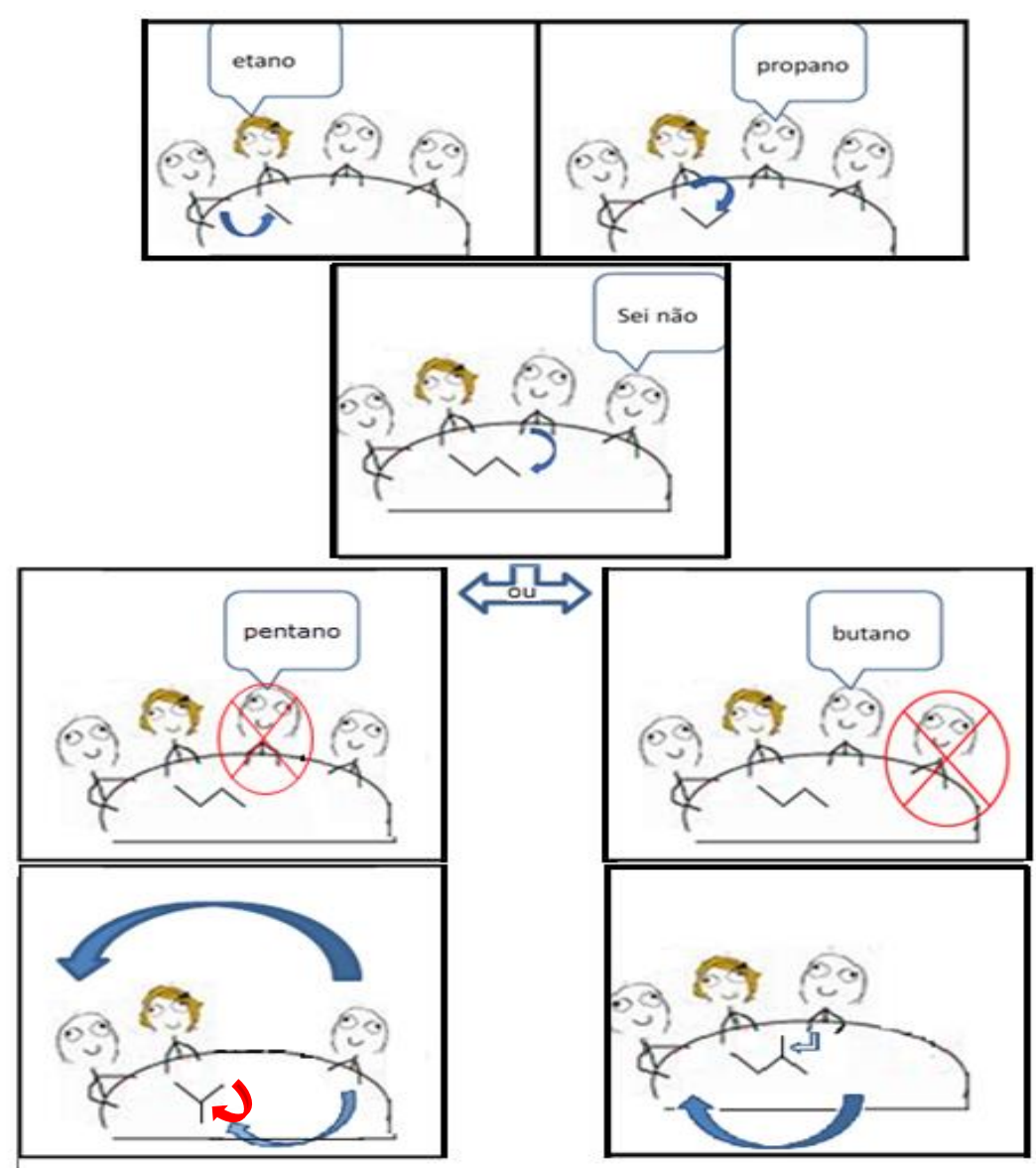

Figura 3: Representação da dinâmica do jogo dos palitos (Fonte: Própria).

Ao nomear a estrutura, cada jogador deverá demonstrar aos demais competidores, indicando com o dedo, a sua escolha da cadeia principal, o nome dos substituintes e sua posição na cadeia, e os demais jogadores corroboram ou refutam a nomenclatura fornecida (figura 4). 


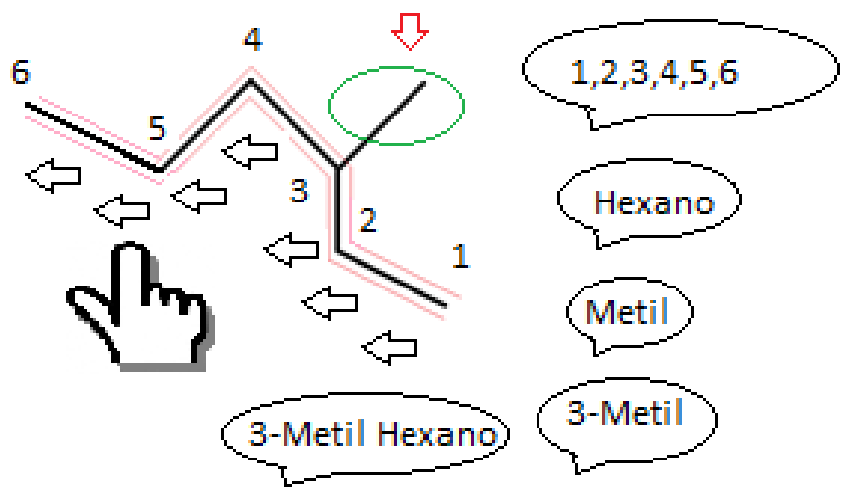

Figura 4: Procedimento seguido pelos jogadores para nomear a estrutura orgânica (Fonte: Própria).

CONTRIBUIÇÃO: Inicialmente teremos estruturas mais simples: um palito (etano), dois palitos (propano). Contudo, com o decorrer do jogo, estruturas cada vez mais complexas irão surgir, o que forçará os estudantes a aplicarem novas regras em adição àquelas que foram utilizadas no início do jogo, estendendo-se assim a todo o conjunto de regras normatizadas pela IUPAC para determinada classe de funções orgânicas.

ABRANGÊNCIA: O jogo permite ainda o desdobramento para a proposição de estruturas cíclicas (figura 5).
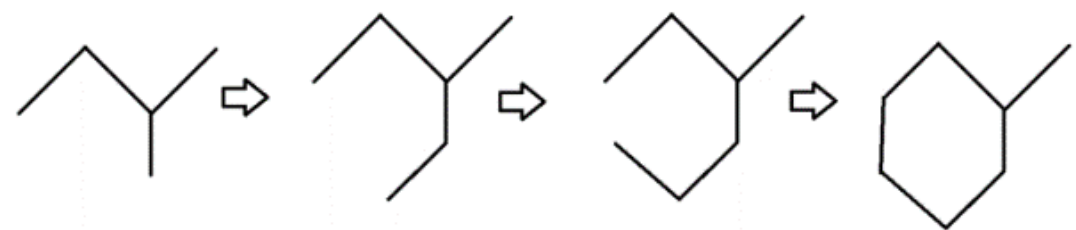

Figura 5: Construção das cadeias carbônicas abertas e fechadas (cíclicas) (Fonte: Própria). (figura 6):

O mesmo procedimento pode ser adaptado para considerar a proposição de insaturações

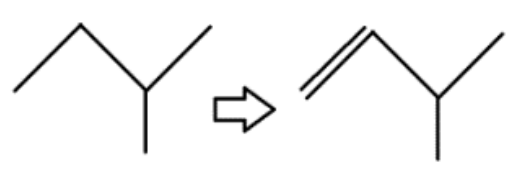

Figura 6: Possibilidade de insaturações na estrutura (Fonte: Própria).

O jogo não precisa ficar restrito a estruturas contendo apenas átomos de carbonos e hidrogênio (hidrocarbonetos). A inclusão de outros elementos (oxigênio, nitrogênio, halogênios, etc) pode acontecer, para isto bastaria pintar-se a extremidade de alguns palitos e associá-los a elementos em particular (figura 7). Com isso, novos grupos funcionais podem ser incluídos no jogo, permitindo que as regras de nomenclatura possam ser mais plenamente abordadas. 


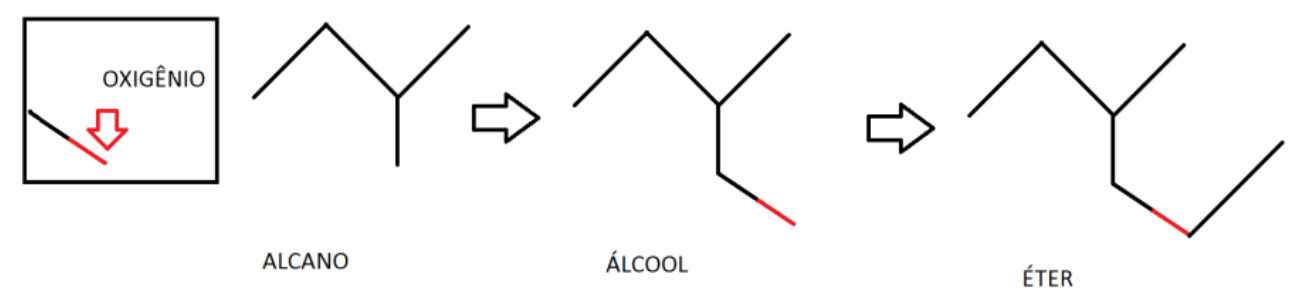

Figura 7: Inclusão de heteroátomos, como o oxigênio, nas estruturas (Fonte: Própria).

PARTICIPANTES: O jogo foi aplicado na disciplina de Metodologia do Ensino de Química II do curso de Química Licenciatura do Centro Acadêmico do Agreste da UFPE no período letivo de 2014.2. Justifica-se a escolha dessa turma pelo fato dessa disciplina ter por co-requisito a disciplina de Química Orgânica I. Isto garantiu o caráter heterogêneo do grupo, com alunos que já haviam trabalhado a representação com fórmula de linhas de ligação há mais tempo e com alunos que haviam sido apresentados a esta representação ainda no mesmo semestre, uma vez que muitos dos estudantes não haviam estudado com aprofundamento essa forma de representação das estruturas orgânicas ainda no ensino médio.

REGISTRO: A aplicação do jogo foi registrada através das fotos das cadeias carbônicas elaboradas pelos estudantes com os palitos no decorrer do jogo. As estratégias, justificativas e explicações, intencionalidades dos alunos foram registradas pelo docente em um diário de campo para posterior análise.

METODOLOGIA DE PESQUISA: A validação do jogo procedeu como uma pesquisa qualitativa quanto à abordagem do problema, de caráter exploratório quanto à sua finalidade e como uma observação participante quanto à forma de coleta de dados. Na pesquisa foram registradas as elaborações dos estudantes na forma das cadeias carbônicas construídas com os palitos no decorrer do jogo e analisada a evolução das estruturas propostas em termos de complexidade ao longo do tempo (rodadas do jogo e partidas), bem como a superação dos estudantes em nomear essas estruturas. Também foram registradas as falas e os comportamentos dos participantes em uma ficha denominada protocolo de acompanhamento da atividade, as quais foram posteriormente analisadas.

Para a análise atribuímos o êxito do propósito educacional do jogo e assim a sua validação ao avanço no desempenho dos alunos participantes no decorrer do próprio jogo, estando esse por sua vez relacionado à complexidade das estruturas elaboradas e à superação das dificuldades pelos estudantes. Buscamos também refletir sobre a contribuição da dinâmica inerente ao jogo dos palitos a este aprendizado confrontando a performance dos participantes as informações registradas no protocolo de acompanhamento da atividade, tal qual: a qualidade da interação, a imersão dos participantes na atividade, ao próprio nível de complexidade proposto pelos jogadores.

\section{RESULTADOS E DISCUSSÕES:}

Propositalmente, no dia em que seria implementado o jogo, não foi trazido nenhum palito, sendo solicitando aos alunos, cerca de 30 minutos antes da aula, que tentassem conseguir na cantina da instituição palitos de dente ou de qualquer outro tipo. Após esse tempo, os alunos da turma haviam adquirido material necessário para que 5 grupos de 6 alunos elaborassem estruturas com mais de 15 ligações. Ressaltamos que, uma vez adquiridos, não houve necessidade de nenhum tratamento (ou adequação) nos palitos. Nesse sentido, destacamos a facilidade de obtenção desse material, caracterizando-o como de baixíssimo ou nenhum custo e não requerendo nenhum tipo de preparo para a sua utilização no jogo. 
Dentre os muitos desafios ao exercício da profissão docente, Alves-Mazzotti (2007) pontua o acúmulo de tarefas atribuídas ao professor a falta de tempo livre para planejar aulas mais atraentes. Nessa perspectiva, a proposição de um recurso didático que não demande custo ou tempo de preparo, que seja flexível (uma vez que pode abordar a nomenclatura de várias classes de compostos orgânicos) e cujas regras sejam de fácil compreensão, se configura como um instrumento acessível ao ensino da disciplina de química orgânica no ensino básico.

No que se refere às dinâmicas que constituem o jogo proposto e o aspecto epistemológico relacionado ao conteúdo abordado, consideramos que o desafio em nomear corretamente os compostos orgânicos se origina na falha em se aplicar as regras estabelecidas pela IUPAC, o que na maioria dos casos este déficit no saber-fazer não diz respeito ao desconhecimento das regras, mas no equívoco de que este fazer é normalmente apartado do entendimento do processo. E que a superação deste obstáculo exige não só a exercitação do procedimento, o que demanda um esforço pessoal do aprendiz, mas também requer, adicionalmente, instigar aos alunos refletir sobre o processo e sobre a escolha ou elaboração de estratégias metacognitivas o que, por sua vez, remete a um processo cognitivo de alto nível (JOU; SPERB, 2006).

Tal processo pode ser percebido pelos estudantes e comentado como forma de incentivo ao colega quando este se mostrou indeciso quanto à atribuição do nome a uma dada estrutura (ver a figura 8 relativas às elaborações consecutivas no jogo e à transcrição do diálogo referente à situação).

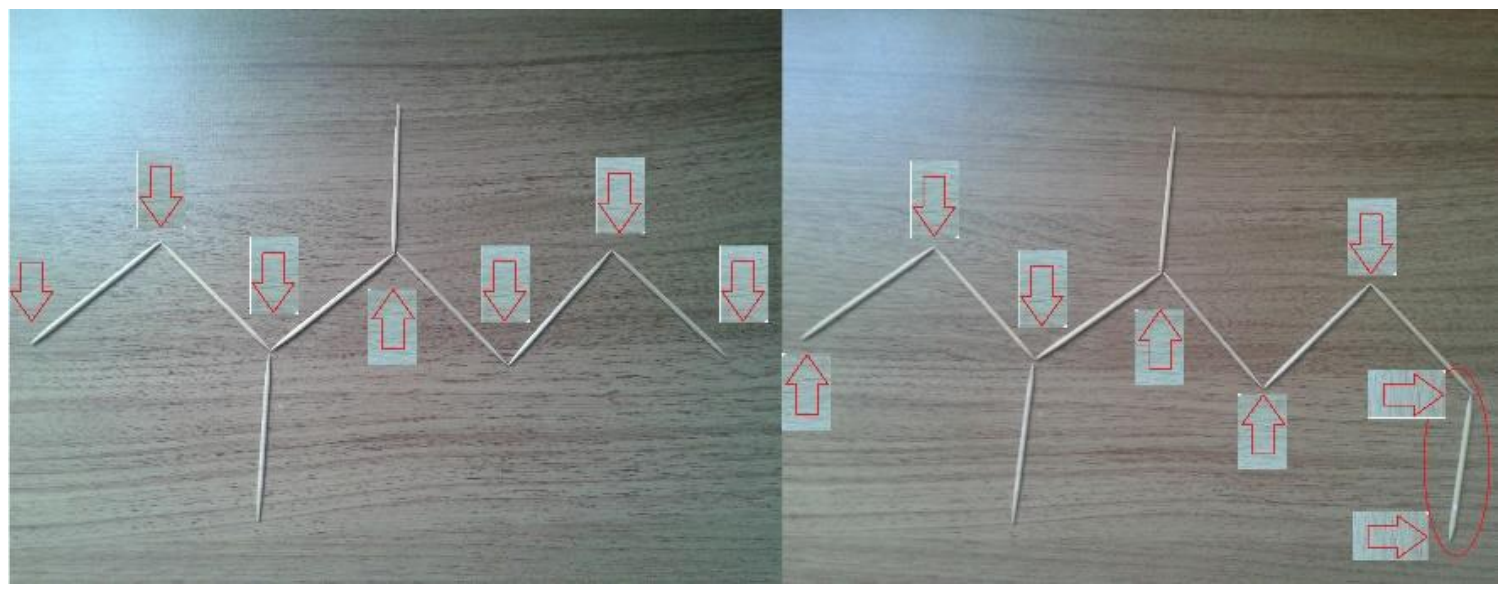

Figura 8: Fotos comparativas de duas situações de jogo (aumento da cadeia) (Fonte: Própria).

Aluno 1: [indeciso]

Aluno 2: presta atenção direitinho o que mudou da estrutura anterior?

Aluno 2: observa aonde foi adicionada (o palito), conta a quantidade de carbonos da cadeia

Aluno 2: mudou a quantidade de carbonos na cadeia principal?

Aluno 1: [nega com a cabeça e responde corretamente]

Foi possível observar, ao longo do jogo, que o desafio que impele cada aluno a construir e nomear as cadeias carbônicas como elaboração pessoal proporcionou um gradativo aumento no nível de complexidade das estruturas propostas e consequentemente uma evolução cognitiva dos alunos, reflexo do esforço espontâneo dos participantes em se manter no jogo.

Esse acréscimo na complexidade é resultante da dinâmica do jogo que tem início sempre com uma única ligação (correspondente a dois átomos de carbono) e a partir daí, a cada rodada, vai sendo 
acrescida uma nova ligação pela adição de um palito. Visto que, em geral, quanto menor a quantidade de carbonos menos complexa tende a ser a estrutura do composto orgânico e mais fácil é nomeá-lo.

Tal afirmação pode ser ilustrada se observarmos a complexidade da estrutura apresentada na 8 a rodada em partidas diferentes (partida 1 e partida 3), mas tendo como participantes o mesmo grupo de alunos (figura 9).

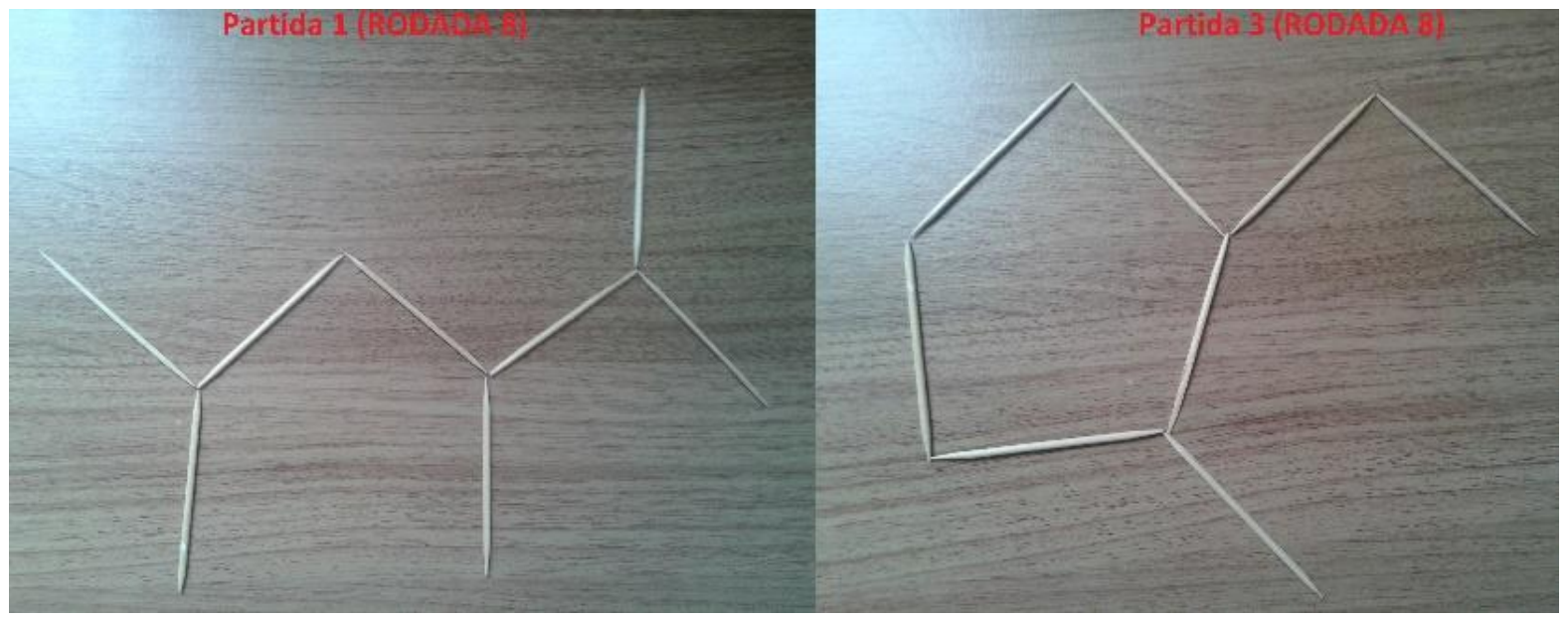

Figura 9: Fotos comparativas de duas situações de jogo (mesma rodada e partidas diferentes) (Fonte: Própria).

É interessante observar que no jogo dos palitos, o mesmo é autorregulado pelos próprios alunos, uma vez que é limitado pelo conhecimento que o jogador desafiante já construiu. Resultando consequentemente em um aumento gradativo, contudo sutil, do nível de habilidades requeridas e de um constante equilíbrio entre desafio e habilidades.

A importância do equilíbrio entre os desafios propostos e as habilidades demandadas para se garantir o engajamento voluntário de um indivíduo em uma determinada ação é enfatizada por Csikszentmihalyi (1999), que afirma que apenas dessa forma é possível alcançar um grau de imersão na atividade que resulte na perda da noção do tempo, além de uma sensação de bem-estar, de prazer ao que ele denomina de estado de fluxo. Nesse sentido, Csikszentmihalyi afirma que caso os desafios estejam além das possibilidades do indivíduo, ocasionaria um estado de ansiedade, preocupação e, por conseguinte, de frustração. Por outro lado, caso os desafios estejam abaixo de suas habilidades e capacidades, o remeteria a um estado de relaxamento, de desinteresse, de apatia e de tédio.

Verificamos ainda que apesar das elaborações serem formuladas individualmente, o processo de apropriação das normas e compreensão da lógica ocorre como um processo coletivo, e socialmente negociado, tendo em vista que a cada nova proposição há a necessidade de o participante seguinte provar a nomenclatura atribuída "argumentando", mostrando aos competidores cada detalhe da cadeia que o levou a designar o nome. Por exemplo, a determinação da cadeia principal, substituinte, posição na cadeia, etc.

Nesse contexto, os estudantes socializam não apenas suas respostas, mas suas estratégias de alcançá-las, e mesmo em caso de erro, a refutação justificada dos colegas permitiu a autorregulação da aprendizagem.

Situações como esta caracterizaram a ocorrência de interações horizontais (aluno-aluno) no jogo e seu papel positivo na assimilação não só da aplicação das normas da IUPAC, mas também das estratégias utilizadas pelos colegas (demais jogadores). 
Observou-se também que o caráter competitivo do jogo proporcionou que os alunos, ao longo das rodadas, se arriscassem mais saindo de suas zonas de conforto. Instigando-os a refletir sobre os conhecimentos já construídos e ampliados no decorrer do próprio jogo, como consequência da mobilização das normas da IUPAC na proposição/nomeação de estruturas mais simples, com o objetivo de transpor raciocínios e entendimentos em elaborações cada vez mais complexas para aumentar, intencionalmente, o nível do desafio aos demais competidores e forçá-los ao erro.

Como exemplo, observamos a elaboração de estruturas cíclicas, cíclicas ramificadas, ou situações em que o acréscimo de um carbono modifica o que em uma rodada anterior se considerava a cadeia principal (ver figura 10).

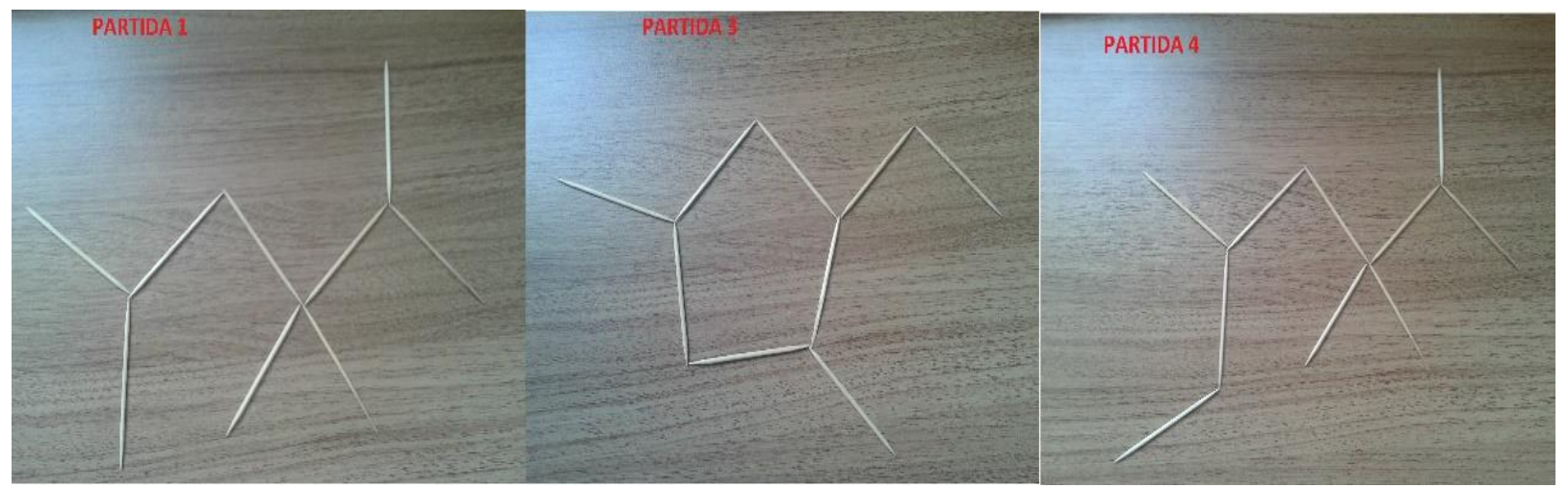

Figura 10: Fotos comparativas de três situações de jogo (aumento da complexidade das estruturas propostas) (Fonte: Própria).

Sobre esse caráter competitivo, vale ressaltar a necessidade imperativa do processo de mediação da atividade pelo professor para garantir um ambiente amistoso, de respeito mútuo e voltado à aprendizagem. Neste sentido, a contribuição do jogo como atividade de aprendizagem transcende o aspecto cognitivo, auxiliando também o desenvolvimento de atitudes (habilidades de caráter interpessoal) como o respeito aos colegas e a compreensão de que perder faz parte da ação de jogar e que ainda assim não invalida o que foi aprendido no processo.

De acordo com Oliveira, Caminha e Freitas (2010), a superação de conflitos decorrentes de situações de interação social que geram frustração, raiva, tristeza originados por interesses incompatíveis entre os envolvidos são naturais e necessários para o desenvolvimento de habilidades interpessoais. O desenvolvimento destas habilidades para a busca de soluções assertivas em conflitos pode ser potencializada em uma situação de aprendizagem oportunizada pelo jogo uma vez que mediadas adequadamente pelo professor.

\section{CONSIDERAÇÕES FINAIS:}

O Jogo dos Palitos pode ser classificado como uma metodologia de custo nulo ou baixíssimo e que não requer tempo algum para preparo do material a ser utilizado.

Do ponto de vista da validação, constatou-se que jogo dos palitos obteve êxito na aprendizagem do procedimento de manipular a representação denominada fórmula de linhas de ligação, bem como de nomear estruturas orgânicas (aplicando as regras da IUPAC) independente do nível de complexidade da estrutura. Verificou-se também nos alunos a elaboração de estratégias para nomear cadeias carbônicas e a compreensão da lógica que regula este procedimento, fato que caracteriza o desenvolvimento de um processo cognitivo superior. 
Mais do que refletir sobre as regras da IUPAC como um procedimento a se realizar, os participantes refletem sobre as ideias dos colegas e sobre seu próprio pensamento em um processo metacognitivo.

Do ponto de vista do propósito lúdico, observou-se um esforço espontâneo dos alunos em se apropriar dos conhecimentos e estratégias utilizadas, ressaltada pela atenção voluntária dos estudantes, mesmo quando já eliminados de uma dada rodada. Outro aspecto que indica o sucesso da função lúdica da atividade proposta foi o ambiente amistoso e livre de pressão, além do comportamento colaborativo dos estudantes.

Adicionalmente destacamos o aspecto positivo da interação (aluno-aluno e aluno-professor) na construção de significados e atribuímos esse resultado ao caráter lúdico da própria metodologia.

Por fim, verificamos que apesar de se tratar de um jogo competitivo, a mediação do professor possibilitou o desenvolvimento de atitudes como o respeito, o espírito de fair-play e a superação do pensamento equivocado de que em um jogo (sobretudo, mas não apenas) educativo só existe prazer em caso de vitória.

\section{REFERÊNCIAS}

ALVES-MAZZOTTI. A. J. Representações da identidade docente: uma contribuição para a formulação de políticas. Ensaio: aval. pol. públ. Educ., Rio de Janeiro, v. 15, n. 57, p. 579-594, 2007.

CUNHA, M.B. Jogos no Ensino de Química: Considerações Teóricas para sua Utilização em Sala de Aula. Revista Química Nova. v. 34, n. 2, p. 92-98, maio 2012.

CAVALCANTI, E. L. D; SOARES, M. H. F. B. O RPG como estratégia de problematização e avaliação do conhecimento químico. Revista Electrónica de Enseñanza de las Ciencias, v. 8, n. 1, p. 255-280, 2009.

CSIKSZENTMIHALYI, M. A descoberta do fluxo: psicologia do envolvimento com a vida cotidiana. Rio de Janeiro: Rocco, 1999.

DOMINGOS, D. C. A.; RECENA, M. C. P. Elaboração de jogos didáticos no processo de ensino e aprendizagem de química: a construção do conhecimento. Ciências \& Cognição, v.15: p. 272-281, 2010.

JOU, G.I.; SPERB, T.M., A metacognição como estratégia reguladora da aprendizagem. Psicol. Reflex. Crit. VOL.19 N.2 Porto Alegre, 2006.

KISHIMOTO, T. M. O Jogo e a educação infantil. São Paulo: Pioneira, 1998.

MIRANDA, D. G. P; COSTA, N. S. Professor de Química: Formação, competências/ habilidades e posturas. 2007. Disponível em: http://www.ufpa.br/eduquim/formdoc.html. Acesso em: 14 de Fevereiro de 2017.

MITRE, S. M.; BATISTA, R.S.; MENDONÇA; J. M.G.; PINTO, N. M. M.; MEIRELLES, C. A. B.; PORTO, C. P.; MOREIRA; T.; HOFFMANN, L. M A. Ciência \& Saúde Coletiva, v. 13 (Sup 2), p.2133-2144, 2008.

OLIVEIRA, G. M. de.; CAMINHA, I. de O.; FREITAS, C. M. S. M. de. Relações de convivência e princípios de justiça: a educação moral na escola. Revista Semestral da Associação Brasileira de Psicologia Escolar e Educacional, São Paulo, v. 14, n. 2, p. 261- 270, jul./dez. 2010.

RODRIGUES, J. A. R. Recomendações da IUPAC para nomenclatura de moléculas orgânicas. Química Nova na Escola, n. 13, p. 22-28, 2001.

ROQUE, N. F.; SILVA, J. L. P. B. A Linguagem e o ensino da química orgânica. Química Nova, n. 4, p. 921-923, 2008.

SOARES, M. H. F. B. Jogos em Ensino de Química: Teoria, Métodos e Aplicações. 1. ed. Guarapari - ES: Editora Ex Libris, 2008. 
SOARES, M. H. F. B. Jogos e Atividades Lúdicas para o Ensino de Química. Editora Kelps, Goiânia, 2013.

SOARES, M. H. F. B.; GARCEZ, E. S. C. Um Estudo da Arte Sobre a Utilização do Lúdico no Ensino de Química. Revista Brasileira de Pesquisa em Educação em Ciências, v.17, n. 1, p. 183-214, 2017.

SUART, R. C.; GOUVÊIA, L. G. Análise das Interações Dialógicas e Habilidades Cognitivas desenvolvidas durante a aplicação de um jogo didático no ensino de química. Ciência \& cognição, v. 19, n. 1, p. 27-46, 2014.

WATANABE, M.; RECENA, C. P. R. Memória orgânica - Um jogo didático útil no processo de ensino e aprendizagem. Universidade Federal de Mato Grosso do Sul, MS, Anais do XIV Encontro Nacional de Ensino de Química (XIV ENEQ), 2008.

ZANON, D. A. V.; GUERREIRO, M. A. S.; OLIVEIRA, R. de. Jogo didático ludo químico para o ensino de nomenclaturas dos compostos orgânicos. Ciência \& cognição, v. 13, n. 1, p. 72-81, 2008.

José Ayron Lira dos Anjos: Professor da área de Ensino de Química do Núcleo de Formação Docente do Centro Acadêmico do Agreste da UFPE onde atua na área de Metodologias Ativas, Aprendizagem Significativa e das Contribuições da Ludicidade no processo de Ensino e Aprendizagem. Atualmente coordenador do subprojeto PIBID Química Caruaru e Docente da linha de Metodologias do Ensino do PPGECM da UFPE.

E-mail: ayronanjos@gmail.com

Ricardo Lima Guimarães: Professor da área de Química Orgânica do Núcleo Interdisciplinar de Ciências Exatas e da Natureza da UFPE. Desenvolve trabalhos em ensino de química na área de experimentação e desenvolvimento de jogos educacionais, além de pesquisa com indicadores naturais (antocianinas), sol-gel e PVA.

E-mail: rlguimaraes@gmail.com 